\title{
Research on Spatial Spillovers of Industries Development in Urban Agglomerations of the Guangdong, Hong Kong and Macau Greater Bay Area
}

\section{—Based on Spatial Panel SpVAR Model}

\author{
Yan $\mathrm{Wu}^{*}$ \\ Beijing Institute of Technology, Zhuhai \\ Zhuhai, China \\ wuyan_zh@163.com \\ *Corresponding author
}

\author{
Jiawei He \\ University of Macau \\ Macau SAR, China
}

\begin{abstract}
Based on data from 2005 to 2016, this paper analyzes the spatial spillovers of urban agglomerations in Guangdong-Hong Kong-Macau Greater Bay Area by using spatial panel SpVAR Model. The results show that the spatial spillover of industry sector of the urban agglomerations in the Pearl River Delta is relatively significant. However, the spatial spillover of the industry sector and service sector of the urban agglomerations in the Great Bay Area need to be strengthened. The industry sector, after being proactively shocked, will bring about positive external impacts, these impacts will last for a while until they vanish. Whereas, the service sector, after being proactively shocked, will also bring about positive impacts, but these impacts will turn negative in the following period of time, these impacts will last as well until they vanish.
\end{abstract}

Keywords-Urban agglomerations in Guangdong-Hong KongMacau Greater Bay Area; Spatial Panel VAR; GMM; Spatial Spillover

\section{INTRODUCTION}

The urban agglomerations of Guangdong, Hong Kong and Macau is a " $9+2$ " model, namely Guangzhou, Shenzhen, Zhuhai, Foshan, Zhongshan, Dongguan, Huizhou, Jiangmen, Zhaoqing, and Hong Kong SAR and Macau SAR. Guangdong, Hong Kong and Macau Greater Bay Area is the world's fourth Greater Bay Area after the Tokyo Bay Area (Advanced Manufacturing Cluster), the New York Bay Area (Financial Cluster), and the San Francisco Bay Area (Technology Innovation Cluster). At present, the Guangdong, Hong Kong and Macau Greater Bay Area is still in its infancy; therefore, strengthening the industrial integration within this area is a pressing challenge.

Sponsors: 1. Zhuhai City's 2017-2018 Annual Philosophy and Social Sciences Planning Project "Research on spatial spillovers of industries development in urban agglomerations of the Guangdong, Hong Kong and Macau Greater Bay Area”, Project No.: 2017YB027

2. Provincial Key Platforms and Major Scientific Research Projects for Universities in Guangdong, "Research on Urban Industrial Transformation and Upgrading in the Pearl River Delta Region from the View of Ecological Economic Efficiency”, Project No.: 2016WQNCX175
Current researches on the industrial development of the agglomerations of Guangdong, Hong Kong and Macau Greater Bay Area are mainly concentrated on three aspects. First, the status quo of industrial clusters and influencing factors by Shouhua WEi, Daning TANG, Xiuyuan SUN (2015) ${ }^{[1]}$, etc. Second, researches on competition, integration, and collaborative development mechanisms in this area, by Yuhong CHENG, Liangwei WANG(2018) ${ }^{[2]}$, and by Yan CHEN, Zhonghao LIN(2018) ${ }^{[3]}$ etc. Third, researches on the spatial effects of urban agglomerations, by Jinyong ZHAN, Hairong ZHANG and Hao LI (2016) ${ }^{[4]}$.

In recent years, some scholars, like Beenstock and Felsenstein (2007) ${ }^{[5]}$, de Assis Cabral, Legey and de Freitas ${ }^{[6]}$, Mutl (2009) ${ }^{[7]}$, Monteiro (2009) ${ }^{[8]}$, Di Giacinto (2010) ${ }^{[9]}$ Márquez and Ramajo (2015) ${ }^{[10]}$, Guoqiang GUO (2013) ${ }^{[11]}$, studied the estimation, verification and application of SpVAR(that is Spatial Panel Vector Autoregression) model. This paper analyzes the spatial spillover of the urban industrial agglomerations in Guangdong, Hong Kong and Macau Greater Bay Area by establishing a spatial panel SpVAR model and applying impulse response function.

II. ANAlysis ON STATUS QUO OF URBAN AgGlOMERATIONS OF INDUSTRIES DEVELOPMENT IN GUANGDONG, HONG KONG AND MACAu GREAT Bey AREA

The GDP of the Guangdong, Hong Kong, and Macau Greater Bay Area in 2016 was approximately 9.35 trillion yuan, among which, the regional GDP of Hong Kong, Guangzhou and Shenzhen was 2,214.25 billion Yuan, 19, 54.744 billion Yuan and 1949.26 billion yuan respectively, ranking the top three in the area. In terms of per capita GDP, in 2016, Macau, Hong Kong, Shenzhen, Guangzhou and Zhuhai ranked top five, with per capita GDP of 479,000 yuan, 302,000 yuan, 167,000 yuan, 142,000 yuan and 135,000 yuan respectively.

From the view of three industrial structures, the proportions of primary industries in Hong Kong and Macau 
are negligible. Whereas, the proportion of agriculture in Zhaoqing, taking up $15.2 \%$, is relatively high. The proportions of secondary industries in Pearl River Delta are significantly high, except for Shenzhen, accounting for 40\%-60\%. The proportions of tertiary industry in Hong Kong and Macau occupy over $90 \%$. (See Table I.)

TABLE I. INDUSTRIAL STRUCTURES OF URBAN AGGLOMERATIONS IN GUANGDONG, HONG KONG AND MACAU GREATER BAY AREA IN 2016

\begin{tabular}{|c|c|c|c|}
\hline City & $\begin{array}{c}\text { GDP/billion } \\
\text { yuan }\end{array}$ & $\begin{array}{c}\text { GDP per } \\
\text { capita/yuan }\end{array}$ & $\begin{array}{c}\text { industrial } \\
\text { structures/percentage }\end{array}$ \\
\hline Guangzhou & 1954.744 & 141933 & $1.2: 29.4: 69.4$ \\
\hline Shenzhen & 1949.260 & 167411 & $0.0: 39.9: 60.1$ \\
\hline Zhuhai & 222.637 & 134548 & $2.0: 48.5: 49.5$ \\
\hline Foshan & 863.00 & 115891 & $1.7: 59.6: 38.7$ \\
\hline Huizhou & 341.217 & 71605 & $5.0: 53.9: 41.1$ \\
\hline Dongguan & 682.769 & 82682 & $0.3: 46.5: 53.2$ \\
\hline Zhongshan & 320.278 & 99471 & $2.1: 52.4: 45.5$ \\
\hline Jiangmen & 241.878 & 53374 & $7.8: 47.6: 44.6$ \\
\hline Zhaoqing & 208.402 & 51178 & $15.2: 48.0: 36.8$ \\
\hline $\begin{array}{l}\text { Pearl River } \\
\text { Delta } \\
\end{array}$ & 67841.85 & 114281 & $1.8: 42.2: 56.0$ \\
\hline Hong Kong & $\begin{array}{l}\text { 2491(billion Hong } \\
\text { Kong dollars) }\end{array}$ & $\begin{array}{c}339531 \\
\text { (HK dollars) }\end{array}$ & $0.1: 7.7: 92.2$ \\
\hline Macau & $\begin{array}{l}\text { 358.2(billion } \\
\text { Macau mop) }\end{array}$ & $\begin{array}{c}554619 \\
\text { (Macau mop) }\end{array}$ & 0.0:6.6:93.4 \\
\hline
\end{tabular}

*Sources: Statistical Yearbooks of the nine cities of the Pearl River Delta; Guangdong Statistical Yearbook; Macau Statistical Yearbook, Hong Kong Statistical Yearbook.

III. RESEARCH ON SPATIAL SPILLOVERS OF INDUSTRIAL DEVELOPMENT IN URBAN AGGLOMERATIONS IN GUANGDONG, Hong Kong and Macau Greater Bay AREA

The spatial spillovers of industrial development in urban agglomerations in Guangdong, Hong Kong and Macau Greater Bay Area can be studied by applying the spatial panel SpVAR model.

\section{A. Differential GMM estimation of SpVAR model}

Based on Monteni (2009) GMM estimation method, Guoqiang GUO(2013) proposed a differential GMM estimation for the spatial dynamic panel SpVAR model.

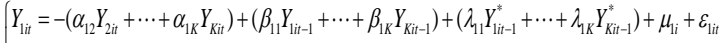

$$
\begin{aligned}
& \left\{Y_{2 i t}=-\left(\alpha_{21} Y_{1 i t}+\alpha_{23} Y_{3 i t} \cdots+\alpha_{2 K} Y_{K i t}\right)+\left(\beta_{21} Y_{1 i t-1}+\cdots+\beta_{2 K} Y_{\text {Kit- }-1}\right)+\left(\lambda_{21} Y_{\text {Iit- }-1}^{*}+\cdots+\lambda_{2 K} Y_{K i t-1}^{*}\right)+\mu_{2 i}+\varepsilon_{2 i t}\right. \\
& \text {... }
\end{aligned}
$$

$$
\text { Let } Y_{i t}=\left[\begin{array}{c}
Y_{1 i t} \\
\cdots \\
Y_{K i t}
\end{array}\right], Y_{i t}^{*}=\left[\begin{array}{c}
Y_{1 i t}^{*} \\
\ldots \\
Y_{K i t}^{*}
\end{array}\right], \quad Y_{k i t}^{*}=w_{i 1} Y_{k 1 t}+\cdots+
$$
$w_{i N} Y_{k N t}, \mathrm{u}_{i}=\left[\begin{array}{c}u_{1 i} \\ \ldots \\ u_{K i}\end{array}\right]$ is fixed effect intercept, $\varepsilon_{i t}=$ $\left[\begin{array}{c}\varepsilon_{1 i t} \\ \cdots \\ \varepsilon_{\text {Kit }}\end{array}\right]$ is residual disturbance. Then we get equation (2).

$$
\left[\begin{array}{ccc}
1 & \cdots & \alpha_{1 K} \\
\vdots & \cdots & \vdots \\
\alpha_{K 1} & \cdots & 1
\end{array}\right] Y_{i t}=\left[\begin{array}{ccc}
\beta_{11} & \cdots & \beta_{1 K} \\
\vdots & \cdots & \vdots \\
\beta_{K 1} & \cdots & \beta_{K K}
\end{array}\right] Y_{i t-1}+\left[\begin{array}{ccc}
\lambda_{11} & \cdots & \lambda_{1 K} \\
\vdots & \cdots & \vdots \\
\lambda_{K 1} & \cdots & \lambda_{K K}
\end{array}\right] Y_{i t-1}^{*}+\mu_{i}+\varepsilon_{i t}
$$

$$
\text { Let } \begin{aligned}
& \alpha= {\left[\begin{array}{ccc}
1 & \cdots & \alpha_{1 K} \\
\vdots & \cdots & \vdots \\
\alpha_{K 1} & \cdots & 1
\end{array}\right], \beta=\left[\begin{array}{ccc}
\beta_{11} & \cdots & \beta_{1 K} \\
\vdots & \cdots & \vdots \\
\beta_{K 1} & \cdots & \beta_{K K}
\end{array}\right], \lambda=\left[\begin{array}{ccc}
\lambda_{11} & \cdots & \lambda_{1 K} \\
\vdots & \cdots & \vdots \\
\lambda_{K 1} & \cdots & \lambda_{K K}
\end{array}\right], } \\
& \text { So } \alpha Y_{i t}=\beta Y_{i t-1}+\lambda Y_{i t-1}^{*}+\mu_{i}+\varepsilon_{i t}
\end{aligned}
$$

Both sides of equation (3) multiply by $\alpha^{-1}$

$$
\begin{aligned}
Y_{i t} & =\alpha^{-1} \beta Y_{i t-1}+\alpha^{-1} \lambda Y_{i t-1}^{*}+\alpha^{-1} \mu_{i}+\alpha^{-1} \varepsilon_{i t} \\
& =\Gamma Y_{i t-1}+\Lambda Y_{i t-1}^{*}+\varphi_{i}+u_{i t}
\end{aligned}
$$

F.O.S $\Delta Y_{i t}=Y_{i t}-Y_{i t-1}$

$$
=\Gamma\left(Y_{i t-1}-Y_{i t-2}\right)+\Lambda\left(Y_{i t-1}^{*}-Y_{i t-2}^{*}\right)+\left(u_{i t}-u_{i t-1}\right)
$$

Then we get the following instrument variable matrix for differential GMM estimation:

$$
Q_{i}=\left[\begin{array}{cccc}
{\left[Y_{i 1}^{\prime}, Y_{i 2}^{\prime}, Y_{i 1}^{* \prime}, Y_{i 2}^{* \prime}\right]^{\prime}} & 0 & \cdots & 0 \\
0 & {\left[Y_{i 1}^{\prime}, Y_{i 2}^{\prime}, Y_{i 3}^{\prime}, Y_{i 1}^{* 1}, Y_{i 2}^{*}, Y_{i 3}^{* \prime}\right]^{\prime}} & \cdots & 0 \\
0 & 0 & \cdots & 0 \\
\vdots & \vdots & \vdots & \vdots \\
0 & 0 & \cdots & {\left[Y_{i 1}^{\prime}, Y_{i 2}^{\prime}, \cdots Y_{i T-2}^{\prime}, Y_{i 1}^{* 1}, Y_{i 2}^{* \prime \prime}, \cdots Y_{i T-2}^{* \prime \prime}\right]^{\prime}}
\end{array}\right]
$$

Both sides of equation (5) multiply by ${ }_{Q_{i}}$, then

$$
\begin{array}{r}
Q_{i} \Delta Y_{i t}=Q_{i} \Delta Y_{i t-1} \Gamma^{\prime}+Q_{i} \Delta Y_{i t-1}^{*} \Lambda^{\prime}+Q_{i} \Delta u_{i t}=Q_{i} \Delta X_{i t} \Pi+Q_{i} \Delta u_{i t} \\
\Delta X_{i t}=\left[\begin{array}{ll}
\Delta Y_{i t-1} & \Delta Y_{i t-1}^{*}
\end{array}\right], \quad \Pi=\left[\begin{array}{l}
\Gamma^{\prime} \\
\Lambda^{\prime}
\end{array}\right]
\end{array}
$$

We calculate the variance-covariance matrix:

$$
\begin{aligned}
& E\left\{\left[\operatorname{Vec}\left(\Delta u_{i t}^{\prime}\right)\right]\left[\operatorname{Vec}\left(\Delta u_{i t}^{\prime}\right)\right]^{\prime}\right\}=E\left\{\left[\begin{array}{c}
\Delta u_{i 4} \\
\Delta u_{i 5} \\
\vdots \\
\Delta u_{i T}
\end{array}\right]\left[\begin{array}{llll}
\Delta u_{i 4}^{\prime} & \Delta u_{i 5}^{\prime} & \cdots & \Delta u_{i T}^{\prime}
\end{array}\right]\right\} \\
& =\left[\begin{array}{cccc}
E\left(\Delta u_{i 4} \Delta u_{i 4}^{\prime}\right) & E\left(\Delta u_{i 4} \Delta u_{i 5}^{\prime}\right) & \cdots & E\left(\Delta u_{i 4} \Delta u_{i T}^{\prime}\right) \\
E\left(\Delta u_{i 5} \Delta u_{i 4}^{\prime}\right) & E\left(\Delta u_{i 5} \Delta u_{i 5}^{\prime}\right) & \cdots & E\left(\Delta u_{i 5} \Delta u_{i T}^{\prime}\right) \\
\vdots & \vdots & \vdots & \vdots \\
E\left(\Delta u_{i T} \Delta u_{i 4}^{\prime}\right) & E\left(\Delta u_{i T} \Delta u_{i 5}^{\prime}\right) & \cdots & E\left(\Delta u_{i T} \Delta u_{i T}^{\prime}\right)
\end{array}\right] \\
& =\left[\begin{array}{ccccccc}
2 \Omega & -\Omega & 0 & \cdots & 0 & 0 & 0 \\
-\Omega & 2 \Omega & -\Omega & \cdots & 0 & 0 & 0 \\
0 & -\Omega & 2 \Omega & \cdots & 0 & 0 & 0 \\
\vdots & \vdots & \vdots & \vdots & \vdots & \vdots & \vdots \\
0 & 0 & 0 & \cdots & -\Omega & 2 \Omega & -\Omega \\
0 & 0 & 0 & \cdots & 0 & -\Omega & 2 \Omega
\end{array}\right]=\Sigma
\end{aligned}
$$$$
E\left\{\left[\operatorname{Vec}\left(\Delta u_{i t}{ }^{\prime}\right)\right]\left[\operatorname{Vec}\left(\Delta u_{j t}{ }^{\prime}\right)\right]^{\prime}\right\}=E\left\{\left[\begin{array}{c}
\Delta u_{i 4} \\
\Delta u_{i 5} \\
\vdots \\
\Delta u_{i T}
\end{array}\right]\left[\begin{array}{llll}
\Delta u_{j 4}^{\prime} & \Delta u_{j 5}^{\prime} & \cdots & \Delta u_{j T}^{\prime}
\end{array}\right]\right\}=0
$$

The calculating steps of the differential GMM estimation is as follows: first, carry out the regression of all the tool variables $Y_{i 1}, Y_{i 2}, \cdots, Y_{i t-2}, Y_{i 1}^{*}, Y_{i 1}^{*}, \cdots, Y_{i t-2}^{*}$ by applying $\Delta Y_{i t-1}$; second, the residual covariance matrix is calculated by using the residual sequence obtained from the regression; then we will get the parameter estimation values by minimizing the covariance matrix, generating a new residual sequence; by 
repeating the above steps, the calculation will stop until the final estimated parameter reaches a convergence condition; after obtaining the final converged parameter estimation value $\hat{\Pi}=\left[\begin{array}{l}\hat{\Gamma}^{\prime} \\ \hat{\Lambda}^{\prime}\end{array}\right]$

$\hat{\Lambda}^{\prime}$, we can find the final value of the residual sequence, thereby obtaining a variance covariance matrix $\hat{\Omega}$;by factorizing matrix $\hat{\Omega}$, we can get the value of $\hat{\Omega}_{0}$ and $\hat{\alpha}^{-1}$, in this way we can also find the value of $\hat{\alpha}$. Therefore, we can get the equations $\hat{\beta}=\hat{\alpha} \hat{\Gamma}, \hat{\lambda}=\hat{\alpha} \hat{\Lambda}$ by calculating, meanwhile we can also calculate the estimated value of the intercept term.

\section{B. Empirical analysis}

1) Variable selection and data source

As proportions of the primary industry in Guangdong, Hong Kong and Macau Greater Bay Area are extremely low, which are basically negligible. Therefore, we use data of the proportions of second industry and tertiary industry of this area in 2005-2016. The definitions and data source are shown below. (See Table II.)

TABLE II. VARIABLE SELECTION AND DAT A SOURCES

\begin{tabular}{|c|c|c|c|}
\hline Variable & Name of variable & Definition of variable & Source \\
\hline Industry & $\begin{array}{l}\text { Proportions of second } \\
\text { industry }\end{array}$ & $\begin{array}{l}\text { added value of secondary } \\
\text { industry(billion Yuan) } \\
\begin{array}{c}\text { regional GDP } \\
\text { (billion Yuan) }\end{array}\end{array}$ & \multirow{2}{*}{$\begin{array}{c}\text { Guangdong } \\
\text { Statistical } \\
\text { Yearbook Data; } \\
\text { Hong Kong and } \\
\text { Macau Data } \\
\text { Sources; World } \\
\text { Bank Database. }\end{array}$} \\
\hline Service & $\begin{array}{l}\text { Proportions of tertiary } \\
\text { industry }\end{array}$ & $\begin{array}{c}\begin{array}{l}\text { added value of tertiary } \\
\text { industry(billion Yuan) }\end{array} \\
\begin{array}{c}\text { regional GDP } \\
\text { (billion Yuan) }\end{array}\end{array}$ & \\
\hline
\end{tabular}

2) Model establishment

Fig.1. and Fig. 2. show the spatial distributions of the variables Industry and Service of the Greater Bay Area in 2016. It can be seen from the figures that the proportions of manufacturing industries in the central region are relatively low while the service industry are relatively high. However, it is totally opposite for both east and west ends. Therefore, clear spatial correlations can be found.

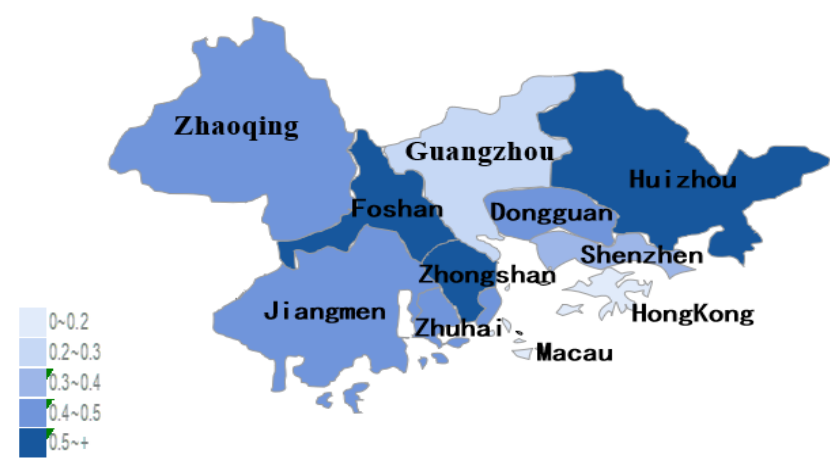

Fig. 1. Spatial distributions of Industry

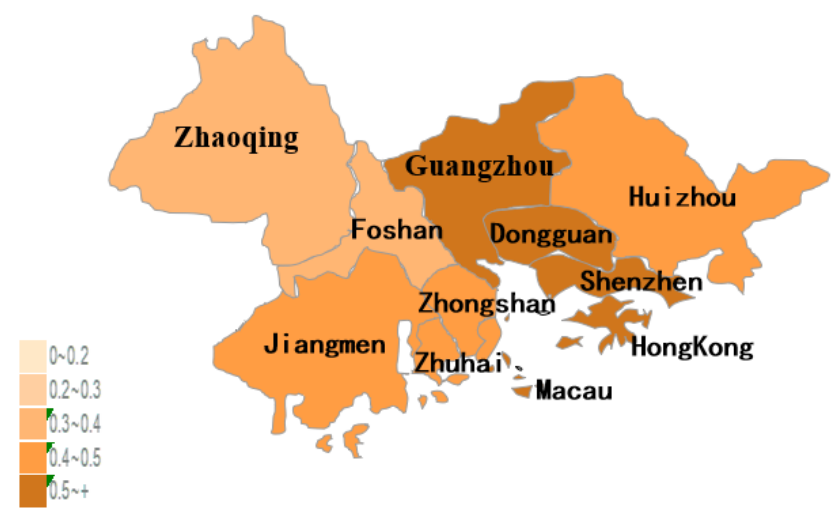

Fig. 2. Spatial distributions of Service

\section{a) Moran's I test for spatial autocorrelation}

Before establishing a spatial data model, it is necessary to test the spatial correlation. And Moran's I test (Moran 1948 ) is frequently used. As the ratios of the secondary and tertiary industries in Hong Kong and Macau are relatively stable, the result will be even more obvious if Hong Kong and Macau are excluded for spatial correlation test. Table III shows the Moran's I test results (See table III) for the Industry and Service variables in the Greater Bay Area and Pearl River Delta. According to the test results, there is a negative correlation in the urban agglomerations in Greater Bay Area, and this negative correlation is particularly significant in the manufacturing industry among nine cities in the Pearl River Delta. Since this paper analyzes the proportions of secondary and tertiary industries separately, the spatial negative correlation implies the industrial transfer effect to some extent. For example, the proportion of secondary industry in Guangzhou is low, but the proportions in neighboring cities (such as Foshan and Huizhou) are relatively higher than that in the farther cities (such as Zhaoqing and Jiangmen), this also suggests a kind of effect that secondary industry transfers to surrounding cities.

TABLE III. MORAN'S I TEST RESULTS FOR THE INDUSTRY AND SERVICE VARIABLES IN THE GREATER BAY AREA AND PEARL RIVER DELT A IN 2016

\begin{tabular}{|c|c|c|c|c|}
\hline \multirow{2}{*}{$\begin{array}{c}\text { Moran's I } \\
\text { test }\end{array}$} & \multicolumn{2}{|c|}{ The Greater Bay Area } & \multicolumn{2}{c|}{ The Pearl River Delta } \\
\cline { 2 - 5 } & Industry & Service & Industry & Service \\
\hline $\mathrm{Z}_{\mathrm{I}}$ & -0.5532 & -0.1320 & -2.4578 & -1.2784 \\
\hline Prob. & 0.3423 & 0.3955 & $0.0195^{*}$ & 0.1762 \\
\hline \multicolumn{3}{|c|}{ Note: * indicates statistical significance at a 5\% significance level. }
\end{tabular}

Furthermore, in order to reflect the spatial distribution features, draw Moran's I (in 2016) scatter plot, see Fig. 3 and Fig. 4. In the figures, the abscissa shows the secondary (or tertiary) industry ratios, and the ordinate shows the spatial lagging periods of the abscissa. In Moran's I scatter plot, each point represents a city, and the scatter plot divides the space into four quadrants, the first quadrant represents highobservation cities surrounded by high-observation cities $(\mathrm{H}-\mathrm{H})$; the second quadrant represents low-observation cities surrounded by high-observation cities (L-H); the third quadrant represents low-observation cities surrounded by low- 
observation cities (L-L); the fourth quadrant represents highobservation cities surrounded by low-observation cities (H-L). The specific city distribution is shown in Table IV. Among the industry variables, Zhaoqing, Jiangmen, and Dongguan fall into the high-high area; Guangzhou, Hong Kong, and Macau fall into the low-high area; Shenzhen falls into the low-low areas; Foshan, Huizhou, Zhongshan and Zhuhai fall into highlow areas. The Service variable in Moran's I scatter plot distribution is basically inverse symmetric with the Industry variable.

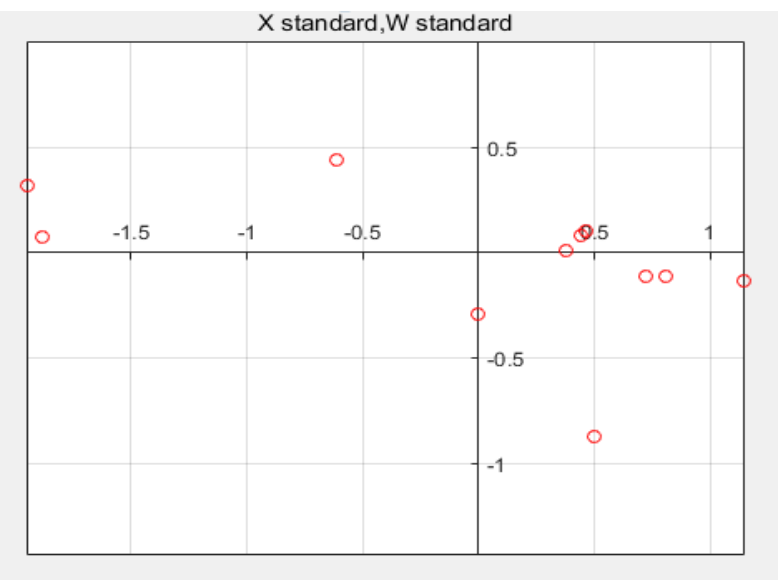

Fig. 3. Moran's I scatter plot for secondary industry distribution

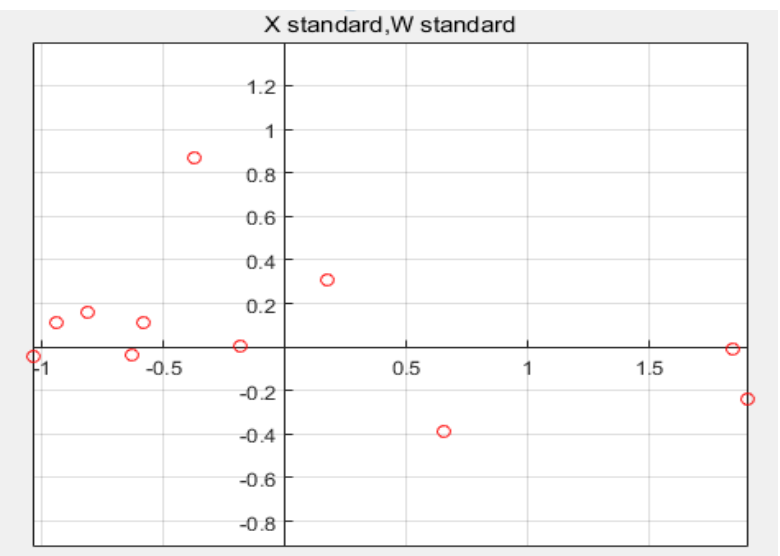

Fig. 4. Moran's I scatter plot for tertiary industry distribution

TABLE IV. MORAN'S I SCATTER CHART FOR CORRESPONDING CITIES IN 2016

\begin{tabular}{|c|c|c|c|c|}
\hline Variable & H - H & L - H & L - L & H - L \\
\hline Industry & $\begin{array}{c}\text { Zhaoqing, } \\
\text { Jiangmen, } \\
\text { Dongguan }\end{array}$ & $\begin{array}{c}\text { Guangzhou, } \\
\text { Hong Kong, } \\
\text { Macau }\end{array}$ & Shenzhen & $\begin{array}{c}\text { Foshan, } \\
\text { Huizhou, } \\
\text { Zhongshan, } \\
\text { Zhuhai }\end{array}$ \\
\hline Service & Shenzhen & $\begin{array}{c}\text { Dongguan, } \\
\text { Zhuhai, } \\
\text { Zhongshan, } \\
\text { Huizhou, } \\
\text { Foshan }\end{array}$ & $\begin{array}{c}\text { Jiangmen, } \\
\text { Zhaoqing }\end{array}$ & $\begin{array}{c}\text { Macau, Hong } \\
\text { Kong, } \\
\text { Guangzhou, }\end{array}$ \\
\hline
\end{tabular}

To sum up, for Industry variable, there is a significant spatial correlation in the urban agglomerations in the Pearl River Delta. If spatial spillover is not considered, a certain degree of bias will occur. Therefore, spatial factors should be added to the model.

\section{b) Unit root and counteraction test for spatial panel}

The panel unit root and panel cointegration tests were performed on the Industry, Service, Industry*, and Service * by using Eviews 9.0. By applying Levin, Lin \& Chu t test, the panel unit root results show that the variables Industry, Service, Industry*, and Service* are all smooth panel data at 5\% significance level, i.e. zero-order monolithic (Table V). By applying Kao Residual Cointegration Test, the spatial panel cointegration test results show that there are cointegration relationships among Industry, Service, Industry* and Service* ( See Table VI).

TABLE V. UNIT ROOT TEST RESULTS FOR SPATIAL PANEL, BASED ON LEVIN, LIN \& CHU T ST ATISTICS

\begin{tabular}{|c|c|c|c|}
\hline \multirow{2}{*}{ Variable } & \multicolumn{3}{|c|}{ Model type } \\
\cline { 2 - 4 } & $\begin{array}{c}\text { Intercept and } \\
\text { trend items }\end{array}$ & Intercept & $\begin{array}{c}\text { Non-intercept } \\
\text { and trend items }\end{array}$ \\
\hline Industry & $-3.80297^{*}$ & $-1.79808^{*}$ & $-5.17688^{*}$ \\
\hline Service & $-3.87826^{*}$ & -0.66170 & 2.22769 \\
\hline $\begin{array}{c}\text { Industry* } \\
\left(=\mathrm{W}^{*} \text { Industry') }\right.\end{array}$ & $-6.86504^{*}$ & 2.19057 & $-6.53486^{*}$ \\
\hline $\begin{array}{c}\text { Service* } \\
\left(=\mathrm{W}^{*} \text { Service') }\right.\end{array}$ & $-4.57839^{*}$ & 0.24469 & 9.40064 \\
\hline \multicolumn{4}{|c|}{ Note: * indicates statistical significance at a 5\% significance level. } \\
\hline
\end{tabular}

TABLE VI. COINTEGRATION TEST RESULTS FOR SP ATIAL PANEL DATA

\begin{tabular}{|c|c|}
\hline Testing method & Test statistics \\
\hline $\begin{array}{c}\text { Kao Residual Cointegration Test(including } \\
\text { intercept items) }\end{array}$ & $-5.039022^{*}$ \\
\hline ADF & Note: * indicates statistical significance at a 5\% significance level. \\
\hline \multicolumn{2}{|c|}{}
\end{tabular}

Industry and Service are both smooth panel data and they have a cointegration relationship. Then Granger Causality Test was performed on variables Industry(*) and Service $\left(^{*}\right)$. Under Pairwise Granger Causality Test, results show that Industry(*) and Service $\left.*^{*}\right)$ are reciprocally affected at $5 \%$ significance level (See Table VII). Therefore, we consider Industry and Service variables as endogenous variables and establish a spatial panel VAR (SpVAR) model.

TABLE VII. PANEL GRANGER CAUSALITY TEST RESULTS

\begin{tabular}{|c|c|c|c|}
\hline Test Method & Null Hypothesis & Statistics & Probability \\
\hline \multirow{7}{*}{$\begin{array}{c}\text { Pairwise Granger } \\
\text { Causality }\end{array}$} & $\begin{array}{c}\text { Industry is not the } \\
\text { Granger reason for } \\
\text { Service }\end{array}$ & 7.89209 & 0.0006 \\
\cline { 2 - 4 } & $\begin{array}{c}\text { Service is not the } \\
\text { Granger reason for } \\
\text { Industry }\end{array}$ & 15.0350 & 0.000002 \\
\cline { 2 - 4 } & $\begin{array}{l}\text { Industry*is not the } \\
\text { Granger reason for } \\
\text { Service* }\end{array}$ & 14.6334 & $2 . \mathrm{E}-06$ \\
\cline { 2 - 4 } & $\begin{array}{c}\text { Service*is not the } \\
\text { Granger reason for } \\
\text { Industry* }\end{array}$ & 27.4387 & $3 . \mathrm{E}-10$ \\
\hline
\end{tabular}

The spatial panel data are stable, and they are cointegrated and bidirectionally affected. Therefore, a spatial dynamic panel SpVAR model is established, and the model is estimated by applying differential GMM method. The specific structure is as follows: 


$$
\begin{gathered}
\left\{\begin{array}{c}
Y_{1 i t}=-\alpha_{12} Y_{2 i t}+\left(\beta_{11} Y_{1 i t-1}+\beta_{12} Y_{2 i t-1}\right)+\left(\lambda_{11} Y_{1 i t-1}^{*}+\lambda_{12} Y_{2 i t-1}^{*}\right)+\mu_{1 i}+\varepsilon_{1 i t} \\
Y_{2 i t}=-\alpha_{21} Y_{1 i t}+\left(\beta_{21} Y_{1 i t-1}+\beta_{22} Y_{2 i t-1}\right)+\left(\lambda_{21} Y_{1 i t-1}^{*}+\lambda_{22} Y_{2 i t-1}^{*}\right)+\mu_{2 i}+\varepsilon_{2 i t}
\end{array}\right. \\
\text { i.e. } \alpha Y_{i t}=\beta Y_{i t-1}+\lambda Y_{i t-1}^{*}+\mu_{i}+\varepsilon_{i t}
\end{gathered}
$$

Among them, $Y_{i t}=\left[\begin{array}{c}\text { Industry } \\ \text { Service }\end{array}\right], Y_{i t}^{*}=\left[\begin{array}{c}\text { Industry }^{*} \\ \text { Service }^{*}\end{array}\right], \mu_{i}$ is a fixed intercept item, $\varepsilon_{i t}$ is a random disturbance.

Assume that $\varepsilon_{i t}$ follows $\mathrm{N}(0, \Omega), \alpha, \beta$, and $\Omega$ are given exactly parameters. Industry*is a spatial variable corresponding to Industry, and Service*is a spatial variable corresponding to Service.

\section{Results analysis}

Both sides of equation (11) multiply by $\alpha^{-1}$, then

$$
\begin{aligned}
Y_{i t} & =\alpha^{-1} \beta Y_{i t-1}+\alpha^{-1} \lambda Y_{i t-1}^{*}+\alpha^{-1} \mu_{i}+\alpha^{-1} \varepsilon_{i t} \\
& =B Y_{i t-1}+C Y_{i t-1}^{*}+\eta_{i}+u_{i t}
\end{aligned}
$$

By differential GMM estimation, estimated results are as follows:

$$
B=\left[\begin{array}{cc}
0.9563 & 0.8387 \\
-0.6656 & 0.5557
\end{array}\right], C=\left[\begin{array}{cc}
-0.4831 & -0.5800 \\
0.7205 & 0.8181
\end{array}\right]
$$

Valid $\operatorname{VAR}(\mathrm{B})$ and $\operatorname{VAR}(\mathrm{C})$ are as follows:

$$
\operatorname{VAR}(B)=\left[\begin{array}{ll}
0.3437 & 0.3985 \\
0.3531 & 0.4093
\end{array}\right], \operatorname{VAR}(C)=\left[\begin{array}{ll}
1.5407 & 1.3892 \\
1.5826 & 1.4270
\end{array}\right]
$$

Based on the above results, Impulse Response Analysis was performed. We chose two cities, Shenzhen and Hong Kong as test subjects. Through the impulse response function, for different cities being shocked by varying variables, impulse response results for all variables in all cities can be obtained (See Fig. 5-12). Fig. 5 and 6 show the impulse responses for all cities based on variable Industry and variable Service, after Shenzhen is given a positive standard deviation shock on variable Industry. While Fig. 7 and 8 show the impulse responses for all cities based on variable Industry and variable Service, after Shenzhen is given a positive standard deviation shock on variable Service. As the values of each city are relatively close in the impulse response function, therefore these eleven lines are actually superimposed in the figures.

The empirical results show that in the urban clusters of Guangdong, Hong Kong and Macau Greater Bay Area, after a city is given a positive standard deviation shock on variable Industry, all cities will be positively influenced in the following period on variable Industry, and this influence will die down rapidly until it vanishes. However, after a city is given a positive standard deviation shock on variable Industry, all cities will be positively influenced in the following period on variable Service, and the influence will also die down rapidly until it vanishes. On the other hand, if a city is given positive standard deviation shock on variable Service, this city will suffer a negative impact on variable Service in the following period, while other cities will be positively impacted on variable Service during the same time, this impact will fade away quickly until it disappears. Whereas, if a city is given a positive standard deviation shock on variable Service, this city will have a positive influence on variable Industry in the following period, while other cities will suffer a negative impact during the same time, this impact will fade away quickly as well until it disappears.

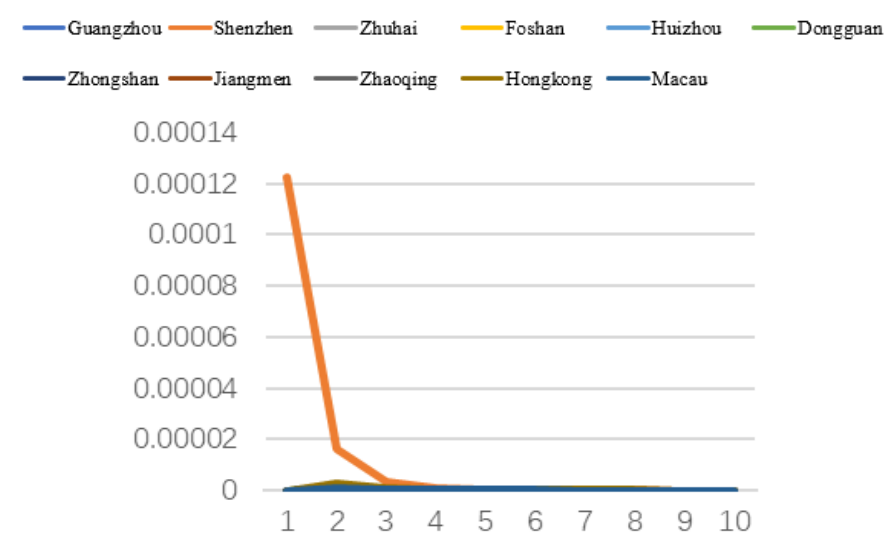

Fig. 5. Impulse response diagram for all cities on Ind if SZ is given a shock on Ind

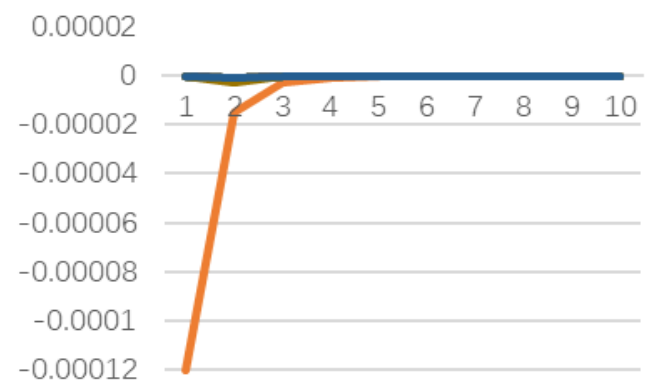

$-0.00014$

Fig. 6. Impulse response diagram for all cities on Ser if SZ is given a shock on Ind

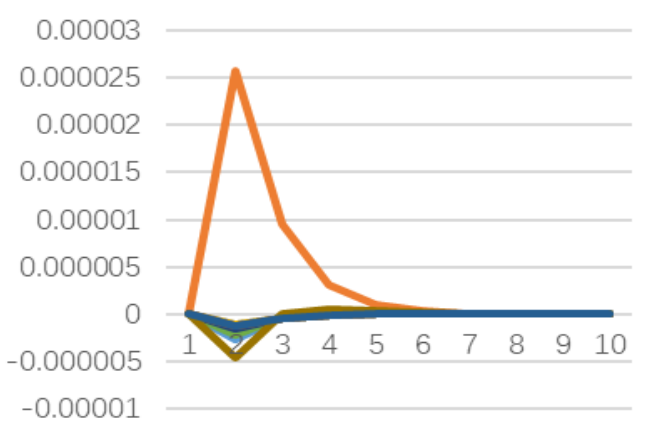

Fig. 7. Impulse response diagram for all cities on Ind if SZ is given a shock on Ser 


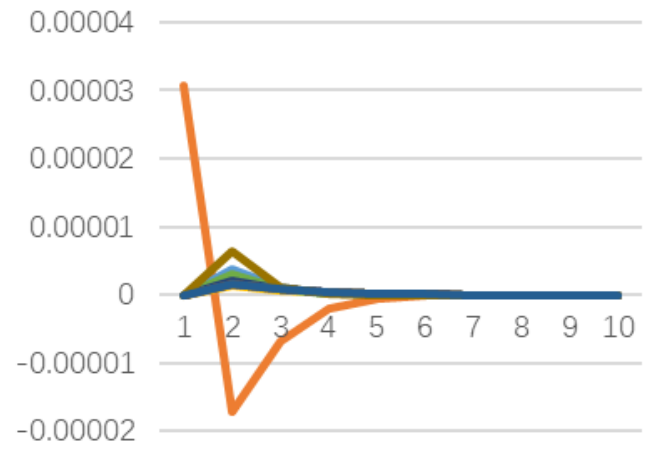

Fig. 8. Impulse response diagram for all cities on Ser if SZ is given a shock on Ser

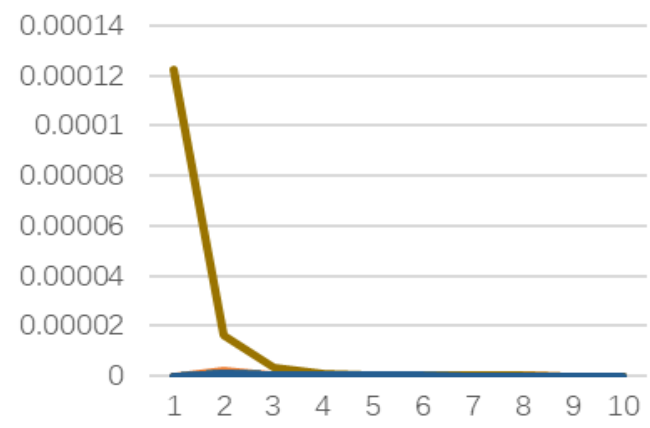

Fig. 9. Impulse response diagram for all cities on Ind if HK is given a shock on Ind

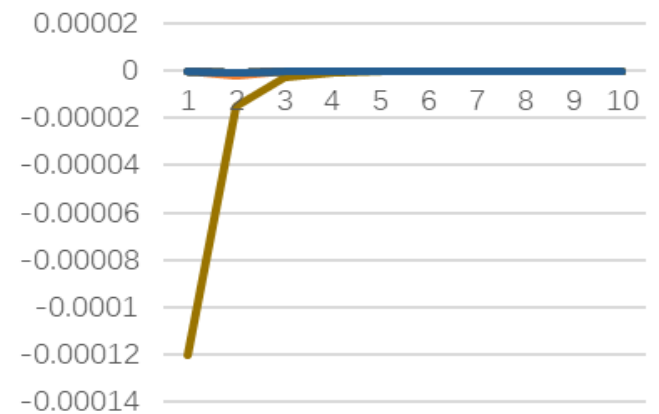

Fig. 10. Impulse response diagram for all cities on Ser if HK is given a shock on Ind

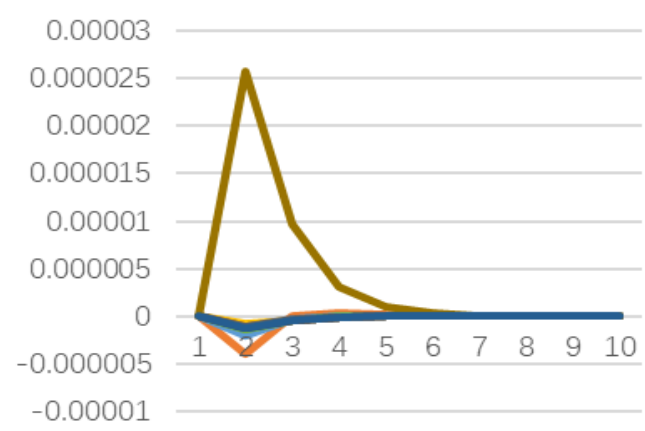

Fig. 11. Impulse response diagram for all cities on Ind if HK is given a shock on Ser

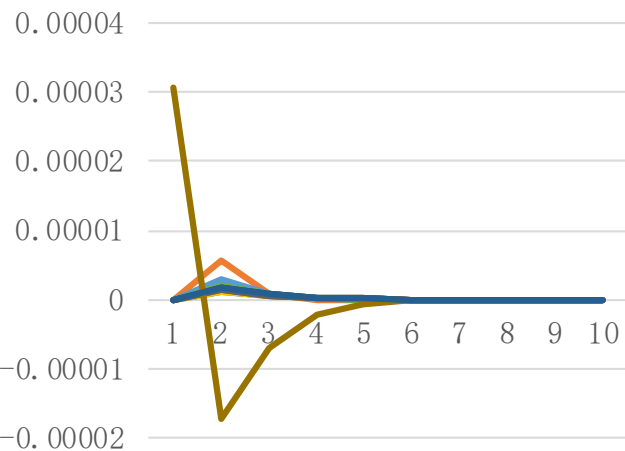

Fig. 12. Impulse response diagram for all cities on Ser if HK is given a shock on Ser

\section{CONCLUSION}

Based on data from 2005 to 2016, this paper analyzes spatial spillover of urban agglomerations in Guangdong-Hong Kong-Macau Greater Bay Area by using spatial panel SpVAR Model. The results show that 1) The spatial spillover of industry sector of the urban agglomerations in the Pearl River Delta is relatively significant. 2) The spatial spillover of the industry sector and service sector of the urban agglomerations in the Great Bay Area need to be strengthened. 3) The industry sector, after being proactively shocked, will bring about positive external impacts; these impacts will last for a while until they vanish. 4) Whereas, the service sector, after being proactively shocked, will also bring about positive impacts, but these impacts will turn negative in the following period of time, these impacts will last as well until they vanish.

\section{REFERENCES}

[1] Shouhua WEI, Danning TANG, Xiuyuan SUN, “Local Economic Structure, Spatial Spillovers and Growth of Manufacturing Industries: Taking the Example of the Yangze River Delta" [J]. Industrial Economics Research. 2015(1): 71-82

[2] Yuhong CHENG, Liangwei WANG, "Study on Competition and Cooperation between Cities in Urban Cluster Growth and Empirical Measurement: A Case Study of Guangdong-Hong Kong-Macao Greater Bay Area”[J].Hong Kong and Macao Journal. 2018(1):45-54

[3] Yan CHEN, Zhonghao LIN, “Grey Correlation Analysis of Industrial Synergetic Development and Synergetic Mechanism Innovation in the Guangdong-Hong Kong-Macao Greater Bay Area” [J]. Journal of Guangdong University of Finance \& Economics. 2018(4):89-97

[4] Jinrong ZHAN, Hairong ZHANG, Hao LI, "Time Evolution and Spatial Distribution of Regional Economic Coordinated Development between Guangdong, Hong Kong and Macao" [J].Urban Development Studies. 2016(8):22-25

[5] Beenstock M, Felsenstein D, “Spatial vector autoregressions”[J]. Spatial Economic Analysis, 2007, 2(2): 167-196.

[6] De Assis Cabral J, Legey L F L, de Freitas M V, "A STANDARD PROCEDURE FOR TESTING THE STABILITY OF SPATIAL VECTOR AUTOREGRESSIVE MODELS (SpVAR)"[J].

[7] Mutl J, Pfaffermayr M, "The Hausman test in a Cliff and Ord panel model”[J]. The Econometrics Journal, 2011, 14(1): 48-76.

[8] Monteiro J A, "Pollution Havens: A Spatial Panel VAR Approach"[J]. 2009. 
[9] Di Giacinto V, "On vector autoregressive modeling in space and time”[J]. Journal of Geographical Systems, 2010, 12(2): 125-154.

[10] Márquez M A, Ramajo J, Hewings G J D, "Regional growth and spatial spillovers: Evidence from an Sp VAR for the Spanish regions”[J]. Papers in Regional Science, 2015, 94(S1): S1-S18.

[11] Guoqiang GUO, "The Theoretical and Applied Research of Spatial Econometric Model” [D]. Wuhan: Huazhong University of Science and Technology, 2013 